\title{
Relative Potency of Testosterone and Dihydrotestosterone in Preventing Atrophy and Apoptosis in the Prostate of the Castrated Rat
}

\author{
A. Stuart Wright, ${ }^{\star}$ Lynn N. Thomas, ${ }^{*}$ Robert C. Douglas, ${ }^{\star}$ Catherine B. Lazier, ${ }^{\ddagger}$ and Roger S. Rittmaster ${ }^{\S}$ \\ $*$ Department of Physiology and Biophysics, ${ }^{\ddagger}$ Department of Biochemistry, and ${ }^{\S}$ Department of Medicine, Dalhousie University, Halifax, \\ Nova Scotia, Canada
}

\begin{abstract}
Although dihydrotestosterone (DHT) is the principal androgen in the prostate, testosterone can also act as an androgen in this tissue. To determine the relative potencies of testosterone and DHT in preventing prostate regression, castrated rats were implanted for $4 \mathrm{~d}$ with varying doses of testosterone in the presence or absence of the $5 \alpha$-reductase inhibitor finasteride. In the absence of finasteride, testosterone in the prostate is converted to DHT, creating an intraprostatic DHT dose response. In the presence of finasteride, this conversion is blocked, and an intraprostatic testosterone dose response is achieved. DHT was 2.4 times more potent than testosterone at maintaining normal prostate weight and duct lumen mass, a measure of epithelial cell function. The two androgens were equipotent at preventing DNA fragementation and expression of testosterone-repressed prostate message, two measures of apoptosis (cell death). The intraprostatic testosterone concentration that results from finasteride treatment in rats is sufficient to inhibit apoptosis but will not maintain normal epithelial cell activity. In conclusion, whereas DHT is more potent than testosterone at stimulating prostate epithelial cell function as measured by ductal mass, the two androgens are equipotent at preventing prostate cell death after castration. These results explain why finasteride causes prostate involution in the rat with minimal evidence of prostate cell death. $(J$. Clin. Invest. 1996. 98:2558-2563.) Key words: dose-response relationship drug • gene expression regulation - finasteride pharmacology • oxidoreductases antagonists and inhibitors • histocytochemistry methods
\end{abstract}

\section{Introduction}

Testosterone is the major circulating androgen in blood and is converted to dihydrotestosterone (DHT) ${ }^{1}$ in the prostate by

This work was presented in part at the 10th International Congress of Endocrinology, San Francisco, CA, June 1996 (Abstract OR 21-6).

Address correspondence to Dr. Roger Rittmaster, Room 809, Gerald Hall, 5305 Morris Street, Halifax, Nova Scotia, Canada B3J1B6. Phone: 902-496-3727; FAX: 902-496-3726.

Received for publication 1 July 1996 and accepted in revised form 19 September 1996.

1. Abbreviations used in this paper: DHT, dihydrotestosterone; G3PDH, glyceraldehyde-3-phosphate dehydrogenase; TRPM-2, testosterone-repressed prostate message; TUNEL, terminal deoxytransferase dUTP-biotin nick end labeling.

J. Clin. Invest.

(C) The American Society for Clinical Investigation, Inc. 0021-9738/96/12/2558/06 \$2.00

Volume 98, Number 11, December 1996, 2558-2563 the enzyme $5 \alpha$-reductase. DHT is considered to be the active androgen in the prostate and results in amplification of the androgen signal (1-3). This is based on the observation that men with congenital $5 \alpha$-reductase deficiency have small prostate glands $(4,5)$, and that DHT concentration in the prostate is $\sim 15-20$-fold higher than testosterone $(6,7)$. The conversion to DHT results in a more stable and potent steroid-androgen receptor complex which enhances prostate function and growth $(1,2,8)$.

In spite of these observations, it is unclear whether the difference between testosterone and DHT is simply one of potency or whether there is a qualitative difference between the actions of these two androgens in the prostate. Previous in vitro studies have indicated that testosterone in sufficiently high concentrations can mimic the actions of DHT in maintaining the stability of the androgen-androgen receptor complex $(1,8)$ and enhancing gene transcription (2). No in vivo studies have previously been published investigating this issue.

After castration, the prostate involutes through a combination of atrophy (reduced epithelial cell function) and apoptosis (programmed cell death). The effect of DHT on these processes can be established by giving varying doses of exogenous testosterone to castrated rats. Because virtually all testosterone is converted to DHT within the prostate by the high intraprostatic concentrations of $5 \alpha$-reductase, a DHT dose response is created. Testosterone replacement in conjunction with a $5 \alpha$-reductase inhibitor (such as finasteride) produces a testosterone dose response within the prostate.

In this study we have examined the relative potency of testosterone and DHT on prostate physiology using this model. Atrophy has been assessed by using morphometrics to determine the size of prostate ducts as a measure of epithelial cell activity. Apoptosis has been evaluated using two markers of programmed cell death: intraprostatic expression of the gene for testosterone-repressed prostate message (TRPM-2, clusterin) and staining for DNA fragmentation by in situ end labeling of damaged DNA strands, an early event in the apoptotic process. Our results demonstrate that the relative potency of testosterone and DHT differs depending on what aspect of prostate physiology is being examined.

\section{Methods}

Animal protocol. Male Sprague Dawley rats (55-d-old, postpubertal) were purchased from Charles River Laboratories (Montreal, Quebec, Canada) and were fed water and Purina Rat Chow ad libidum. The androgen manipulation was achieved with testosterone implants (Innovative Research of America, Sarasota, FL). For the intraprostatic DHT dose response, rats were divided into seven groups: intact, castrated, and castrated plus $0.05,0.10,0.30,0.50$, or $0.70 \mathrm{mg}$ subcutaneous testosterone implants ( $21 \mathrm{~d}$ release). The intraprostatic testosterone dose response was achieved with testosterone implant and the selective $5 \alpha$-reductase inhibitor finasteride (Proscar; Merck, 
Sharp, \& Dohme Research Laboratories, Rahway, NJ) to inhibit intraprostatic conversion of testosterone to DHT. The rats were divided into nine groups: intact, intact treated with finasteride, castrated, and castrated plus $0.05,0.10,0.25,2.5,5.0$, or $15.0 \mathrm{mg}$ testosterone implants in conjunction with finasteride treatment. The maximum testosterone dose in both studies was chosen, based on preliminary experiments, as a dose sufficient to ensure maintenance of normal prostate size. Castration was performed via scrotal route under ketamine/xylazine anesthesia. Testosterone pellets were implanted subcutaneously at the time of castration via midscapular incision. Finasteride treated rats were given $40 \mathrm{mg} / \mathrm{kg}$ daily subcutaneous injections in $1 \mathrm{ml}$ sesame oil, $10 \%$ ethanol vehicle (6). The rats were killed after $4 \mathrm{~d}$ of treatment because the rate of apoptosis in castrated rats is maximal at this time point $(6,9)$. The prostates were immediately removed, weighed, and prepared for histological examination or frozen in liquid nitrogen for determination of androgen concentration and mRNA levels.

Intraprostatic androgen concentration. Intraprostatic testosterone and DHT levels were measured in 100-200 mg homogenized prostate tissue by radioimmunoassay after extraction in Delsal's solution (4:1 methylal/methanol). The androgens were purified over silica columns and separated by celite chromatography as previously published (6). Procedural recoveries were $70 \pm 7 \%($ mean $\pm S D)$ for testosterone and $65 \pm 11 \%$ for DHT. Mean assay sensitivities (assuming a mean recovery) were $0.62 \mathrm{nmol} / \mathrm{kg}$ tissue $(0.18 \mathrm{ng} / \mathrm{g})$ for testosterone and 0.72 $\mathrm{nmol} / \mathrm{kg}$ tissue $(0.21 \mathrm{ng} / \mathrm{g})$ for DHT. All testosterone and DHT measurements were within the working range of the assay. Interassay coefficients of variation for the entire procedure were $11.1 \%$ for testosterone and $9.9 \%$ for DHT.

Morphometrics. Whole ventral prostates were formalin fixed, embedded in paraffin, and sectioned at $5 \mu \mathrm{m}$ for histological analysis. Duct lumen mass was determined by morphometrics using a Zeiss Videoplan morphometric computer and a Zeiss microscope fitted with a JVC video camera as described previously (9). The percent area occupied by prostate ducts was multiplied by the ventral prostate weight to provide duct lumen mass. Analysis was accomplished by sampling 10 random sections per slide (thus ensuring that both peripheral and central regions of the ventral prostate were sampled) and 3-5 prostates per group.

Staining for DNA breaks. Apoptotic cells were quantified by staining for double stranded DNA fragmentation using a modification of the terminal deoxytransferase dUTP-biotin nick end labeling (TUNEL) technique (9). Biotinylated dATP was added to fragmented ends of DNA using terminal deoxynucleotidyltransferase. The number of epithelial cells staining for biotinylated dATP were expressed as a percent of total epithelial cells. Analysis was accomplished by counting a minimum of 1,000 epithelial cells per slide and 3-5 prostates per group. Results were expressed as a percentage of total epithelial cells.

RNA isolation. RNA was isolated from prostatic tissue using a modification of a cesium chloride method (10). Prostates were pulverized under liquid nitrogen with mortar and pestle and suspended in $1 \mathrm{ml} / 100 \mathrm{mg}$ tissue solution $\mathrm{D}$ ( $4 \mathrm{M}$ guanidine isothiocyanate [GITC], $25 \mathrm{mM}$ sodium citrate, $\mathrm{pH} 7.0,0.5 \% n$-lauryl sarkosyl [wt/ vol], and 0.1 M 2-mercaptoethanol). Samples were homogenized with a Polytron homogenizer (Brinkman, Rexdale, Ontario, Canada) at $8,000 \mathrm{rpm}$ for $30 \mathrm{~s}$, diluted to $9 \mathrm{ml}$ with solution D and layered over $\mathrm{CsCl}(5.7 \mathrm{M})$ and centrifuged overnight at $175,000 \mathrm{~g}$. The RNA samples were further purified by phenol/chloroform extraction (10). The RNA was suspended in TE $(100 \mathrm{mM}$ Tris- $\mathrm{HCl}, \mathrm{pH} 7.5,10 \mathrm{mM}$ EDTA, $\mathrm{pH}$ 8.0) buffer and the concentration determined by spectrophotometry at $260 \mathrm{~nm}$.

Slot blots. Slot blots were prepared from total RNA samples with a few modifications to the method (11). Each RNA sample was serially diluted eight times from 5 to $0.04 \mu \mathrm{g}$ for slot blot wells. Sample buffer was added (50\% formamide, $17 \%$ [37\% wt $/ \mathrm{vol}]$ formaldehyde, $10 \% 5 \times$ MOPS [0.1 M 3-\{N-morpholino\}propanesulfonic acid, $0.05 \mathrm{M}$ sodium acetate, $0.01 \mathrm{M}$ EDTA], and distilled $\mathrm{H}_{2} \mathrm{O}$ in a final volume of $35 \mu \mathrm{l}$ ), and the samples heated for $15 \mathrm{~min}$ at $65^{\circ} \mathrm{C}$. The samples were removed to ice and $15 \mathrm{ml}$ TE buffer was added. The samples were loaded into wells and allowed to incubate for $30 \mathrm{~min}$. Gentle suction was applied and then the wells washed again with TE buffer. The membrane was UV cross-linked using a UV Stratalinker 2400 (Stratagene, La Jolla, CA).

${ }^{32} \mathrm{P}$-labeled cDNA probes were made for TRPM-2 and G3PDH mRNA as described previously (6). Blots were prehybridized in hybridizing mixture $\left(50 \%\right.$ deionized formamide, $0.05 \mathrm{M} \mathrm{NaH}_{2} \mathrm{PO}_{4}, \mathrm{pH}$ $6.5,5 \times \mathrm{SSC}, 0.5 \mathrm{mg} / \mathrm{ml}$ yeast tRNA, $1 \times$ Denhardt's solution, $1 \%$ SDS) for $2 \mathrm{~h}$ and then hybridized with probes (6). The slot blots were exposed to the film (NEN DuPont, Mississauga, Ontario, Canada) for varying lengths of time while stored at $-70^{\circ} \mathrm{C}$. Films were developed using a Kodak automatic film processor. The relative expression of each transcript was determined by densitometric analysis of the autoradiograms using an Apple Color OneScanner on a Macintosh 6100/ 60 computer and the public domain NIH Image program (PB95500195GEI; U.S. National Institutes of Health, Springfield, VA). Densitometric results were plotted against total RNA concentration and regression performed on the linear portion of the curve. TRPM-2 mRNA signals were corrected for differences in loading by comparison to the level of G3PDH mRNA, measured by reprobing the stripped blots with ${ }^{32} \mathrm{P}$-labeled G3PDH cDNA.

Statistics. Values are expressed as the mean \pm SEM. Statistical analyses of significance were performed using StatView (Abacus Concepts, Berkeley, CA) on a Macintosh 6100/60 computer. Multiple regression analysis was used to determine whether linear regression lines were significantly different from each other $(P<0.05)(12)$. Analysis of nonlinear graphs for statistical significance between testosterone and DHT dose responses were performed using two-way ANOVA. $P<0.05$ was considered statistically significant.

\section{Results}

Validation of animal model. The implants of testosterone were validated for constant delivery. Rats $(n=30)$ were castrated and implanted with $5 \mathrm{mg}$ testosterone pellets and killed on days $0,2,4,8,9,10$, and 11 . Serum testosterone and prostate weight were stable for at least $11 \mathrm{~d}$ and maintained in the range $349 \pm 18 \mathrm{ng} / \mathrm{dl}$ and $0.447 \pm 0.015 \mathrm{~g}$, respectively. There was no significant variation over time for either serum testosterone or prostate weight.

Intraprostatic androgen dose responses. Mean intraprostatic testosterone and DHT concentrations were $0.62 \pm 0.23$ and $17.8 \pm 1.8 \mathrm{ng} / \mathrm{g}(n=7)$ in intact animals, $0.84 \pm 0.29$ and $0.42 \pm 0.18 \mathrm{ng} / \mathrm{g}$ in castrated animals $(n=8)$, and $19 \pm 0.61$ and $0.98 \pm 0.17 \mathrm{ng} / \mathrm{g}$ in intact animals given finasteride $(n=5 ; 40$ $\mathrm{mg} / \mathrm{kg} / \mathrm{d}$ ). In castrated rats given testosterone pellets in the presence or absence of treatment with finasteride, the relationship between intraprostatic androgen concentration and serum testosterone is illustrated in Fig. 1. The two curves appear to have a biphasic relationship with a more rapid rise in intraprostatic androgen concentration at low concentrations of serum testosterone. In the intraprostatic DHT dose response, the maximum intraprostatic testosterone concentration was 1.29 ng/g (Fig. 1). In the intraprostatic testosterone dose response, the maximum intraprostatic DHT was also $1.29 \mathrm{ng} / \mathrm{g}$ (Fig. 1). There was no significant increase in these concentrations with increasing dose of testosterone pellets.

Prostate weight. Prostate weight varied linearly with intraprostatic DHT $(r=0.971, P=0.006)$ and testosterone $(r=$ $0.975, P=0.001$ ) concentrations (Fig. 2). The slopes derived for the two dose responses were significantly different from each other $(P<0.01)$. Analysis of the slopes demonstrated that within the prostate, DHT was 2.4 times as potent as tes- 


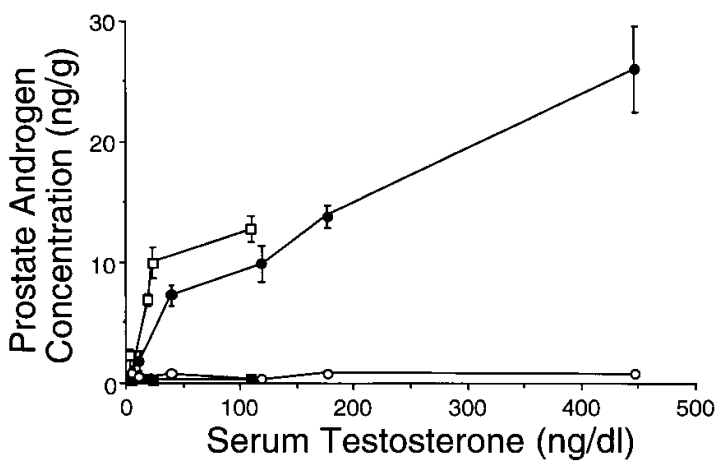

Figure 1. Intraprostatic androgen concentration as a function of serum testosterone. Male Sprague Dawley rats (300-350 g) were castrated and given subcutaneous testosterone implants, with or without the $5 \alpha$-reductase inhibitor finasteride, and sacrificed $4 \mathrm{~d}$ later. In the presence of finasteride, intraprostatic testosterone exhibited a dose response (closed circles) and intraprostatic DHT did not (open circles). In the absence of finasteride, intraprostatic DHT exhibited a dose response (open squares) and intraprostatic testosterone (closed squares) did not. Values are expressed as mean \pm SEM.

tosterone in maintaining ventral prostate weight. The intraprostatic DHT concentration $(9.5 \mathrm{ng} / \mathrm{g})$ required to maintain normal prostate weight $(449 \pm 16 \mathrm{mg})$ was 2.4 times less than the concentration of testosterone $(22.9 \mathrm{ng} / \mathrm{g})$ needed to maintain normal weight.

Duct lumen mass. Duct lumen mass was determined from morphometric analysis of paraffin embedded prostates as the percent area occupied by the ducts multiplied by the weight of the ventral prostate. Lumen mass varied linearly with intraprostatic DHT $(r=0.922, P=0.026)$ and testosterone $(r=0.974$, $P=0.001$ ) concentrations (Fig. 3). The slopes derived for the two dose responses were significantly different from each other $(P<0.01)$. Analysis of the slopes demonstrated that DHT was 2.4 times as potent as testosterone. The intraprostatic DHT concentration $(8.4 \mathrm{ng} / \mathrm{g})$ required to maintain nor-

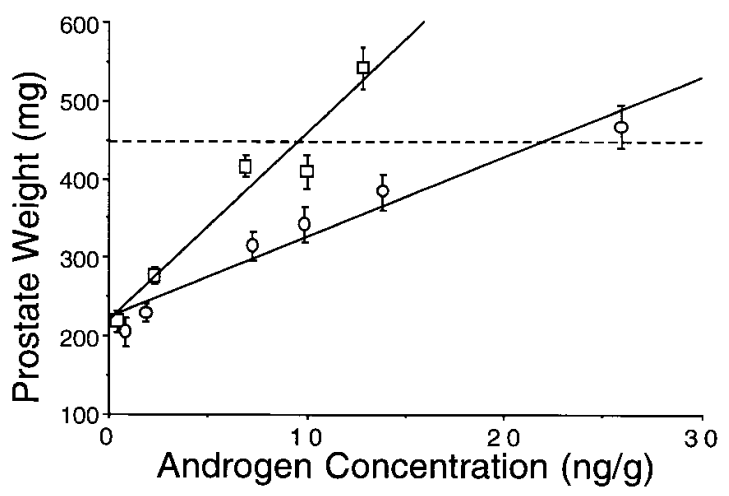

Figure 2. Ventral prostate wet weights for DHT and testosterone as a function of intraprostatic androgen concentration. Testosterone dose response (open circles). DHT dose response (open squares). The dotted line represents normal ventral prostate weight, $449 \pm 16 \mathrm{mg}(n=31)$. For purposes of comparison, the ventral prostate wet weights were $311 \pm 13 \mathrm{mg}(n=16)$ for intact rats treated with finasteride for $4 \mathrm{~d}$ and $206 \pm 18 \mathrm{mg}(n=29)$ for rats castrated $4 \mathrm{~d}$ previously. The equations of the lines were $\mathrm{y}=24 \mathrm{x}+220, \mathrm{r}^{2}=0.94$ and $\mathrm{y}=10 \mathrm{x}+220, \mathrm{r}^{2}=0.96$, for the DHT and testosterone dose responses, respectively.

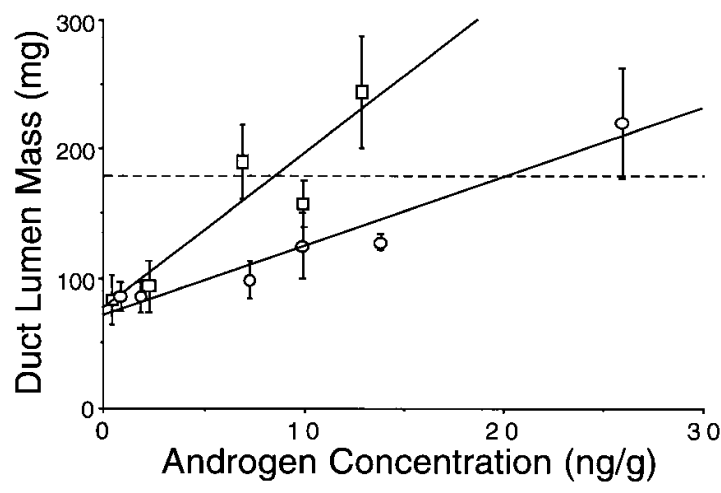

Figure 3. Duct lumen mass as a function of intraprostatic androgen concentration. Testosterone dose response (open circles). DHT dose response (open squares). The lumen mass was $177 \pm 18 \mathrm{mg}$ for intact controls, $121 \pm 6 \mathrm{mg}$ for intact rats treated with finasteride and $85 \pm 9$ $\mathrm{mg}$ for castrated rats. The dotted line represents normal duct lumen mass. The equations of the lines were $\mathrm{y}=12 \mathrm{x}+76, \mathrm{r}^{2}=0.85$ and $\mathrm{y}=$ $5 \mathrm{x}+71, \mathrm{r}^{2}=0.95$, for the DHT and testosterone dose responses, respectively.

mal duct lumen mass $(177 \pm 18 \mathrm{mg})$ was 2.5 times less than the concentration of testosterone $(21.2 \mathrm{ng} / \mathrm{g})$ needed to maintain normal duct lumen mass.

Inhibition of apoptosis. Cells undergoing apoptosis were quantified by end labeling for DNA breaks using TUNEL staining and by measuring intraprostatic TRPM-2 mRNA concentrations. TUNEL staining was highest in the prostates of castrated rats and lowest in prostates from intact rats and intact rats treated with finasteride. The percentage of cells staining for DNA breaks was reduced to the normal range $(0.13 \pm$ $0.09, n=8$ ) by an intraprostatic concentration of $10 \mathrm{ng} / \mathrm{g}$ for either testosterone or DHT. The two curves for DHT and testosterone dose responses did not differ significantly from one another (Fig. $4 a$ ).

Expression of TRPM-2 increases with androgen withdrawal $(13,14)$ and has been used extensively as a marker of apoptotic activity in the prostate $(13,15-17)$. TRPM-2 mRNA for the intraprostatic dose responses was quantified using slot blots (Fig. $4 \mathrm{~b}$ ). The specificity of the slot blot results was confirmed with Northern blots. The TRPM-2 and G3PDH mRNAs were each resolved as one band consistent with previous studies (6). To compare levels of the mRNA from the different treatment groups, pooled RNA from the prostates of the same castrated and intact rats was used on each slot blot. Each sample was expressed as a percentage of the castrate control and normalized against G3PDH mRNA. The results show that TRPM-2 mRNA levels were reduced to the intact range by a $10 \mathrm{ng} / \mathrm{g}$ intraprostatic concentration of either testosterone or DHT. The two curves showed no significant difference from each other.

\section{Discussion}

In the prostate, androgens stimulate cell proliferation and cell secretory activity and inhibit cell death. DHT, and not testosterone, has been determined to be the active androgen in the prostate based on its higher intraprostatic concentration, selective retention in prostatic nuclei (18), and the presence of small prostates in $5 \alpha$-reductase-deficient men $(4,5)$. Testoster- 

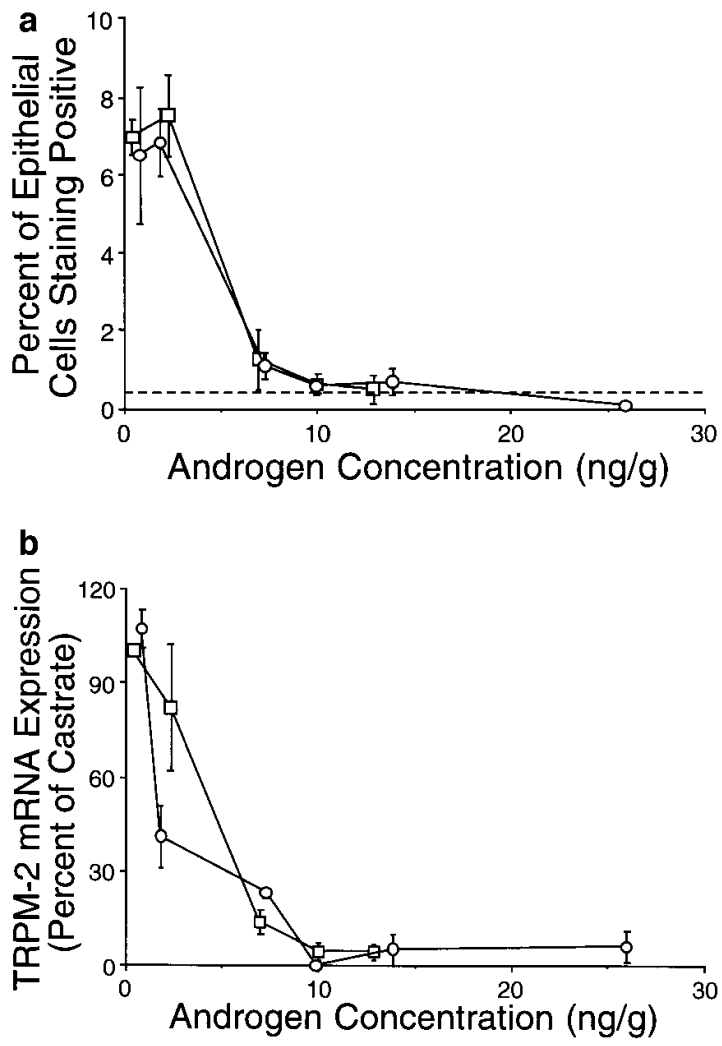

Figure 4. (a) Percent of epithelial cells staining positive for DNA fragmentation as a function of intraprostatic androgen concentration. Testosterone dose response (open circles). DHT dose response (open squares). TUNEL staining (expressed as percent of epithelial cells staining positive) was $0.05 \pm .03(n=8), 6.49 \pm 1.74(n=8)$, and $0.30 \pm 0.12(n=5)$ for prostates from intact, castrated, and intact rats treated with finasteride, respectively. The dotted line represents TUNEL staining in the prostates of normal rats (mean $+2 \mathrm{SD})$. (b) TRPM-2 mRNA expression in ventral prostate as a function of androgen concentration. Testosterone dose response (open circles). DHT dose response (open squares). The data are expressed as a percentage of the TRPM-2 signal in prostatic RNA from castrated rats. No signal was detectable for prostatic RNA from intact rats or intact rats treated with finasteride.

one has not been thought to have a direct effect within the prostate based on its low concentration in this gland. Various studies have been done to test this hypothesis, but the action of testosterone itself on the prostate in vivo has not previously been investigated in a dose dependent manner. This issue has become more important with the use of $5 \alpha$-reductase inhibitors that markedly increase intraprostatic testosterone concentration. The serum testosterone required to accumulate DHT in the prostate is less than the serum testosterone necessary to accumulate the same concentration of testosterone in the prostate (Fig. 1). This is probably a reflection of the selective retention of DHT in the prostate (18) and reduced degradation resulting from stability of the DHT-androgen receptor complex $(1,8)$.

Our results indicate that the relative potency of DHT and testosterone in the prostate differs depending on whether atrophy or apoptosis is being examined. Prostate wet weight is a global measure of altered physiology of the prostate. We found that DHT is 2.4 times more potent than testosterone at maintaining the weight of the rat ventral prostate after castration. Duct lumen mass, which we have used as measure of secretory activity within the prostate, also indicates that DHT is 2.4-2.5 times more potent than testosterone. The potency effect was evident when either the slopes of the dose response curves or the concentration of each intraprostatic androgen required to maintain normal prostate weight or duct lumen mass was compared. In determining mean duct lumen area, our random sampling measured both proximal and distal duct size. Although the epithelial cells of the proximal duct are largely androgen-independent, the diameter of the ducts throughout the prostate should reflect the net secretory activity of the prostate epithelium. This relationship would likely not have been true had we measured epithelial cell width (in which case only epithelial cells of the distal ducts would have decreased in diameter with androgen withdrawal).

Interestingly, we found that testosterone and DHT were equipotent at preventing apoptosis in the castrated rat. We used two different measures of apoptosis: staining for broken strands of DNA and quantification of TRPM-2 mRNA concentrations in homogenized ventral prostate. Although DNA breaks are seen with both apoptosis and necrosis, cell death in the androgen-deprived prostate is due to apoptosis and not necrosis. Our previous research has also demonstrated an excellent correlation between TRPM- 2 mRNA concentrations and other measures of apoptosis (staining for apoptotic bodies and for tissue transglutaminase) (9). Because of the steepness of the dose-response with DNA staining (Fig. $4 a$ ), we could not rule out a small difference in potency between testosterone and DHT using this measure alone. However, the TRPM-2 dose response (Fig. $4 b$ ) actually suggests that low doses of testosterone may be more potent than DHT in inhibiting expression of this gene. Although we do not believe this to be the case, the TRPM- 2 results clearly demonstrate that DHT is not more potent than testosterone.

The in vivo effects that we show differ from previous in vitro studies. Deslypere et al. used Chinese hamster ovary cells cotransfected with a plasmid encoding androgen receptor cDNA and a reporter plasmid containing the androgen-responsive mouse mammary tumor virus promoter to determine whether binding parameter differences could explain the physiologic differences between testosterone and DHT action (2). Chinese hamster ovary cells show very little conversion of steroids to other metabolites and finasteride was added to prevent even trace amounts of DHT forming from testosterone administration. Both hormones achieved the same maximal reporter gene activity but DHT was $\sim 10$ times more potent than testosterone when half maximal activity was examined. Grino et al. used cultured fibroblasts from the genital skin of a $5 \alpha-$ reductase-deficient male to measure testosterone interaction with the human androgen receptor (1). The fibroblast monolayer has abundant androgen receptor but very little $5 \alpha$-reductase and what residual remained was further inhibited by the addition of finasteride. Grino et al. found that testosterone and DHT have the same maximal binding to receptor but the affinity of testosterone binding is about half that of DHT. Kinetic experiments indicated that testosterone exhibits a fivefoldfaster dissociation rate from androgen receptor than DHT. Thermolability experiments, which measure receptor complex stability, demonstrated that 10 times the concentration of testosterone was required to mimic the stability of receptor seen 
with DHT. Zhou et al. used recombinant androgen receptor in COS cells to investigate the relative effectiveness of testosterone and DHT in receptor stabilization (8). It was demonstrated that the half maximal dissociation rate was three times faster for testosterone than DHT and that testosterone was less effective at stabilizing the receptor against degradation. These results along with those of Grino et al. (1) lead to the conclusion that the DHT-androgen receptor complex was at least two to three times more potent than the testosterone androgen receptor complex and that the decreased potency could be overcome by mass action. Our results for measurement of prostate weight and atrophy support this conclusion, but the fact that testosterone and DHT are equipotent in the prevention of cell death was not predicted by any of these in vitro models. We hypothesize that the relative potency of testosterone and DHT for the genes involved in apoptosis in the prostate is different from their relative potency for the genes involved in prostate secretory activity.

Because testosterone can be metabolized to estradiol, it is possible that the intraprostatic testosterone dose response may not solely be due to the effects of testosterone but also to the effects of estrogens. The presence of estrogen receptor has been demonstrated in rat $(19,20)$ and human prostates $(21$, 22 ). Because serum testosterone concentration is similar between normal rats and those treated with finasteride, any increase in estrogen concentration would have to arise from local aromatization of androgens to estrogens. Aromatase has been found in both the prostate stroma and epithelium by immunocytochemistry (23). However, the presence of aromatase activity within the prostate has never been conclusively demonstrated. Indirect measurements of estrogen production (using formation of tritiated water from tritiated androgens) have been shown to correlate poorly with formation of estrogens in the prostate. Using direct measurements of estrogen production, Brodie et al. (24) could find no evidence of aromatase activity in human prostate, even when testosterone metabolism was inhibited with $5 \alpha$-reductase inhibitors. In addition, aromatase inhibitors have no effect on canine benign prostatic hyperplasia (25) and have had little effect on human benign prostatic hyperplasia (26). Although it would be unlikely that estrogens could mimic the ability of androgens to prevent apoptosis in the rat prostate, we cannot rule out a role of local estrogen production in our testosterone dose response.

One of the concerns that we had was whether the small amount of DHT present in the prostate after treatment with finasteride was enough to potentiate the high concentration of testosterone. Our results indicate that low levels of testosterone and DHT are unable to significantly inhibit cell atrophy or apoptosis in our model. Low concentrations of testosterone and DHT in both of our dose response studies had no significant effect on maintenance of prostate weight, duct lumen mass, or the markers of apoptosis, especially DNA fragmentation. Therefore, the low DHT concentration within the prostates of the testosterone dose response is unlikely to enhance testosterone effectiveness. In previous in vivo studies it was demonstrated that the level of intraprostatic DHT that results from castration is not high enough to have an effect on inhibition of cell atrophy, inhibition of apoptosis or cell proliferation (27). Kyprianou et al. also showed that complete elimination of androgens in male Sprague Dawley rats by castration and adrenalectomy did not induce any further reduction in the prostates than castration alone. DHT appears to have a critical threshold above which the prostatic concentration must rise in order to stimulate prostatic cell number (28).

Finasteride treatment in rats has been shown to reduce the intraprostatic DHT concentration to near castrate levels but raises the testosterone concentration to the same value as intraprostatic DHT concentrations in intact rats $(6,9)$. The effect on the prostate of finasteride and other $5 \alpha$-reductase inhibitors is a high degree of cell atrophy with minimal evidence of cell loss. Finasteride administration does not result in upregulation of TRPM-2 mRNA in the prostates of treated rats $(6,7,16)$, although there was an increase in TRPM-2 protein using another $5 \alpha$-reductase inhibitor (3). Inhibition of apoptosis occurs at an intraprostatic testosterone concentration $(\sim 10 \mathrm{ng} / \mathrm{g}$ tissue) approximately half that seen with finasteride treatment and a DHT concentration half that of a normal intact rat. On the other hand, the concentration of testosterone in the prostate needed to maximally stimulate secretory activity is greater than the intraprostatic testosterone concentration in rats treated with finasteride. Our results offer an explanation for the inability of $5 \alpha$-reductase inhibitors to decrease the prostate weight to the same extent as castration.

In summary, DHT appears to be more potent than testosterone at stimulating prostate epithelial cell function as measured by ductal mass, but the two androgens were equipotent at preventing prostate cell death after castration. Our study provides an explanation for the inability of $5 \alpha$-reductase inhibition to reduce prostate weight to the same extent as castration. In order to understand the molecular mechanisms that might explain our observations, detailed studies will be needed to examine the effect of testosterone and DHT on specific genes in the prostate.

\section{Acknowledgments}

The authors wish to thank Dr. Martin Tenniswood (Alton-Jones Research Center, Lake Placid, NY) for donating the TRPM-2 cDNA and Merck Frosst Canada for donation of finasteride. Technical assistance was provided by Andrew Manning.

This work was supported by grants from the Medical Research Council of Canada (grant MA-9619 to R.S. Rittmaster), Merck Frosst Canada and Merck Sharp \& Dohme Research Laboratories.

\section{References}

1. Grino, P.B., J.E. Griffin, and J.D. Wilson. 1990. Testosterone at high concentrations interacts with the human androgen receptor similarly to dihydrotestosterone. Endocrinology. 126:1165-1172.

2. Deslypere, J.-P., M. Young, J.D. Wilson, and M.J. McPhaul. 1992. Testosterone and $5 \alpha$-dihydrotestosterone interact differently with the androgen receptor to enhance transcription of the MMTV-CAT reporter gene. Mol. Cell. Endocrinol. 88:15-22.

3. Lamb, J.C., H. English, P.L. Levandoski, G.R. Rhodes, R.K. Johnson, and J.T. Isaacs. 1992. Prostatic involution in rats induced by a novel $5 \alpha$-reductase inhibitor, SK\&F 105657: role for testosterone in the androgenic response. Endocrinology. 130:685-694.

4. Imperato-McGinley, J., T. Gautier, K. Zirinsky, T. Hom, O. Palomo, E. Stein, E.D. Vaughan, J.A. Markisz, E. Ramirez de Arellano, and E. Kazam. 1992. Prostate visualization studies in males homozygous and heterozygous for 5 $\alpha$-reductase deficiency. J. Clin. Endocrinol. Metab. 75:1022-1026.

5. Wilson, J.D., J.E. Griffin, and D.W. Russell. 1993. Steroid 5 alpha-reductase 2 deficiency. Endocr. Rev. 14:577-593.

6. Rittmaster, R.S., K.E. Magor, A.P. Manning, R.W. Norman, and C.B. Lazier. 1991. Differential effect of $5 \alpha$-reductase inhibition and castration on androgen-regulated gene expression in rat prostate. Mol. Endocrinol. 5:10231029.

7. Shao, T.C., A. Kong, P. Marafelia, and G.R. Cunningham. 1993. Effects of finasteride on the rat ventral prostate. J. Androl. 14:79-86.

8. Zhou, Z.X., M.V. Lane, J.A. Kemppainen, F.S. French, and E.M. Wilson. 1995. Specificity of ligand-dependent androgen receptor stabilization: receptor 
domain interactions influence ligand dissociation and receptor stability. Mol. Endocrinol. 9:208-218.

9. Rittmaster, R.S., A.P. Manning, A.S. Wright, L.N. Thomas, S. Whitefield, R.W. Norman, C.B. Lazier, and G. Rowden. 1995. Evidence for atrophy and apoptosis in the ventral prostate of rats given the 5 alpha-reductase inhibitor finasteride. Endocrinology. 136:741-748.

10. Davis, L.G., M.D. Dibner, and J.F. Battey. 1986. Basic Methods in Molecular Biology. Elsevier Science Publishing Co. Inc., New York. 130-133.

11. Davis, L.G., M.D. Dibner, and J.F. Battey. 1986. Basic Methods in Molecular Biology. Elsevier Science Publishing Co. Inc., New York. 147-149.

12. Sanford, W. 1985. Applied Linear Regression, Second edition. John Wiley and Sons, Toronto, Canada. 179-185.

13. Furuya, Y., and J.T. Isaacs. 1993. Differential gene regulation during programmed cell death (apoptosis) versus proliferation of prostatic glandular cells induced by androgen manipulation. Endocrinology. 133:2660-2666.

14. Leger, J.G., M.L. Monpetit, and M. Tenniswood. 1987. Characterization and cloning of androgen repressed mRNAs from rat ventral prostate. Biochem. Biophys. Res. Commun. 147:196-203.

15. Buttyan, R., C. Olsson, J. Pintar, C. Chang, M. Bandyk, P.-Y. Ng, and I.S. Sawczuk. 1989. Induction of the TRPM-2 gene in cells undergoing programmed death. Mol. Cell. Biol. 9:3473-3481.

16. Russo, P., J.A. Warner, R. Huryk, G. Perez, and W.D.W. Heston. 1994. TRPM-2 gene expression in normal rat ventral prostate following castration and exposure to diethylstilbestrol, flutamide, MK-906, (finasteride), and coumarin. Prostate. 24:237-243.

17. Briehl, M.M., and R.L. Miesfeld. 1991. Isolation and characterization of transcripts induced by androgen withdrawal and apoptotic cell death in the rat ventral prostate. Mol. Endocrinol. 5:1381-1388.

18. Anderson, K.M., and S. Liao. 1968. Selective retention of dihydrotestosterone by prostatic nuclei. Nature (Lond.). 219:277-279.

19. Jung-Testas, I., M.-T. Groyer, J. Bruner-Lorand, O. Hechter, E-E. Bau- lieu, and P. Robel. 1981. Androgen and estrogen receptors in rat ventral prostate epithelium and stroma. Endocrinology. 109:1287-1289.

20. Kuiper, G., E. Enmark, M. Pelto-Huikko, S. Nilsson, and J-A. Gustafsson. 1996. Cloning of a novel estrogen receptor expressed in rat prostate and ovary. Proc. Natl. Acad. Sci. USA. 93:5925-5930.

21. Brolin, J., L. Skoog, and P. Ekman. 1992. Immunohistochemistry and biochemistry in detection of androgen, progesterone, and estrogen receptors in benign and malignant human prostatic tissue. Prostate. 20:281-295.

22. Schulze, H., and S. Claus. 1990. Histological localization of estrogen receptors in normal and diseased human prostates by immunocytochemistry. Prostate. 16:331-343.

23. Matzkin, H., and M.S. Soloway. 1992. Immunohistochemical evidence of the existence and localization of aromatase in human prostatic tissues. Prostate. 21:309-314.

24. Brodie, A.M., C. Son, D.A. King, K.M. Meyer, and S.E. Inkster. 1989 Lack of evidence for aromatase in human prostatic tissues: effects of 4-hydroxyandrostenedione and other inhibitors on androgen metabolism. Cancer Res. 49: $6551-6555$.

25. Oesterling, J., P. Juiewicz, J. Walters, J. Strandenburg, R. Steele, L. Ewing, and D. Coffey. 1988. Aromatase inhibition in the dog. II. Effect on growth, function, and pathology of the prostate. J. Urol. 139:832-839.

26. Schweikert, H.U., U.W. Tunn, U.F. Habenicht, J. Arnold, T. Senge, H. Schulze, F.H. Schroder, J.H. Blom, O. Ennemoser, W. Horniger et al. 1993. Effects of estrogen deprivation on human benign prostatic hyperplasia. J. Steroid Biochem. Mol. Biol. 44:573-576.

27. Kyprianou, N., and J.T. Isaacs. 1987. Biological significance of measurable androgen levels in the rat ventral prostate following castration. Prostate. 10:313-324.

28. Kyprianou, N., and J.T. Isaacs. 1987. Quantal relationship between prostatic dihydrotestosterone and prostatic cell content: critical threshold concept. Prostate. 11:41-50. 